\title{
Controlled trial of oligopeptide versus amino acid diet in treatment of active Crohn's disease
}

\author{
J C Mansfield, M H Giaffer, C D Holdsworth
}

Gastroenterology Unit, Royal Hallamshire Hospital, Sheffield

J C Mansfield

M H Giaffer

C D Holdsworth

Correspondence to: Dr J C Mansfield,

Gastroenterology Unit,

Royal Victoria Infirmary,

Newcastle upon Tyne

NE1 4LP.

Accepted for publication 23 March 1994
Figure 1: Study design. Active Crohn's disease was defined as symptomatically active disease with a $C D A I$ $>150$ and at least one abnormal blood test indicative of activity.

Remission criteria were a reduction in CDAI of 100 points or $40 \%$, control of symptoms and withdrawal of all treatment including corticosteroids.

\section{Abstract}

Elemental diets are effective in inducing remission in active Crohn's disease, but how they exert this therapeutic effect is unclear. In a previous study a whole protein containing diet proved less effective than one in which food antigens were excluded, suggesting that exclusion of food antigens from the gut was a possible mechanism. This study was designed to test whether an oligopeptide diet of hydrolysed proteins was as effective as an amino acid based diet. These diets were equally antigen free but with different nitrogen sources. Forty four patients with active Crohn's disease were randomised in a controlled trial of amino acid versus oligopeptide diet. The feeds were given by nasogastric tube in equicaloric quantities and were the sole form of nutrition. Treatment was continued for four weeks although failure to improve by day 10 resulted in withdrawal. Quantitative leucocyte scintigraphy was used to investigate the effect of diet treatment on gut inflammation. Clinical and nutritional responses to treatment were also measured. Sixteen patients entered remission (including withdrawal of corticosteroids), six patients could not tolerate the nasogastric tube, and 22 patients failed to respond. The two diets were equally effective. Patients who responded had a rapid drop in clinical index of disease activity and a major reduction in the bowel uptake of leucocytes on scintigraphy. The oligopeptide and amino acid based enteral feeds were equally effective at inducing remission in active Crohn's disease. With both diets clinical improvement was accompanied by a reduction in intestinal inflammation. (Gut 1995; 36: 60-66)

Keywords: Crohn's disease, amino acid diet, oligopeptide diet.
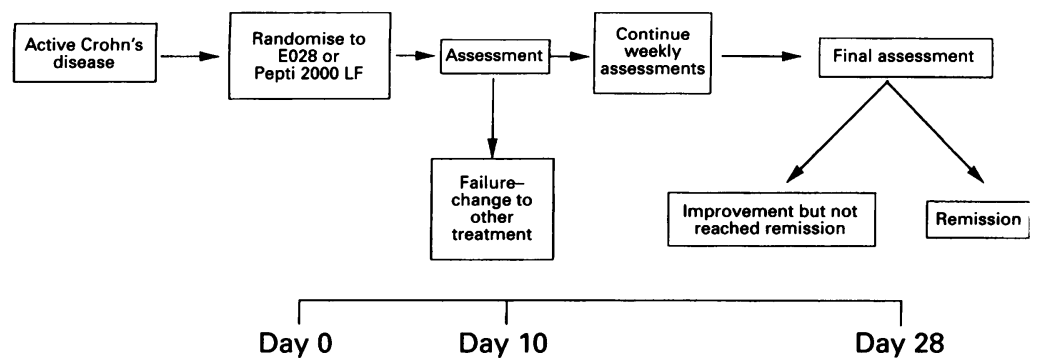

The mechanism by which formula diets can induce remission in active Crohn's disease and the choice of type of diet are controversial. ${ }^{12}$ Bowel rest, antigen removal, and improved nutrition may all contribute to the clinical response. A reduction in gastrointestinal protein loss, a decrease in intestinal permeability, and a reduction in faecal excretion of indium labelled leucocytes have all been shown, ${ }^{3-5}$ suggesting a direct effect of diet on inflammatory activity in the gut. In children, improved nutritional indices and improved growth can be achieved using an elemental diet. $^{6-8}$ The remission induced by elemental diet is often longlasting and can be achieved in many patients with Crohn's disease who had been dependent on, or refractory to, corticosteroids. 910

Three different types of enteral or 'formula' feeds are available: amino acid based (elemental), protein hydrolysate (oligopeptide), and whole protein containing (polymeric). The different forms of nitrogen content have clear differences in the presentation of antigen to the intestinal mucosa. Whole protein containing diets present a range of dietary antigens, determined by the protein source, often milk protein. Oligopeptide based diets, made by protein hydrolysis, have a mean peptide chain length of four or five amino acids, which is too short for antigen recognition or presentation. Amino acid based diets, also known as chemically defined diets, are created by mixing of single amino acids and are entirely antigen free.

Four studies have compared amino acid and polymeric diets in Crohn's disease. ${ }^{11-14}$ The studies differed in important aspects of their design, including the degree of malnutrition and whether corticosteroids were coadministered, and the results are conflicting. A survey among practising gastroenterologists has shown that the commonest current practice in the United Kingdom is to use an amino acid based feed. ${ }^{15}$ Both amino acid and oligopeptide based diets have been compared with corticosteroids in the treatment of active Crohn's disease. Three randomised controlled trials all showed amino acid diets to be as effective as corticosteroid treatment in achieving remission. ${ }^{16-18}$ Two randomised controlled trials have compared oligopeptide diet with drug treatment, using a combination of corticosteroids and sulphasalazine. In a small study in children both treatments seemed similar, ${ }^{7}$ but in a larger study in adults drug treatment was superior. ${ }^{19}$

This study was designed to test whether two diets, differing mainly in the form of dietary nitrogen, but both being antigen free, were 
TABLE I Nutritional composition of E028 and Pepti-2000 LF Liquid

\begin{tabular}{|c|c|c|}
\hline & E028 & Pepti-2000 LF \\
\hline Presentation & $\begin{array}{l}\text { Dry powder } \\
100 \text { g packets } \\
\text { made up to } 500 \mathrm{ml}\end{array}$ & $\begin{array}{l}\text { Liquid } \\
500 \mathrm{ml} \text { bottles }\end{array}$ \\
\hline Osmolality & $500 \mathrm{mOsm} / \mathrm{kg}$ & $470 \mathrm{mOsm} / \mathrm{kg}$ \\
\hline $\begin{array}{l}\text { Energy }(\mathrm{kcal} / 100 \mathrm{ml}) \\
\text { Energy distribution }(\%)\end{array}$ & 80 & 100 \\
\hline \multicolumn{3}{|l|}{ Energy distribution (\%) } \\
\hline $\begin{array}{l}\text { Protein equivalent } \\
\text { Fat }\end{array}$ & 11 & 16 \\
\hline $\begin{array}{l}\text { Fat } \\
\text { Carbohydrate }\end{array}$ & 16 & 9 \\
\hline $\begin{array}{r}\text { Carbohydrate } \\
\text { Nitrogen source }\end{array}$ & 73 & 75 \\
\hline Nitrogen source & $\begin{array}{l}100 \% \text { free synthetic } \\
\text { aminoacids }\end{array}$ & $\begin{array}{l}\text { Protein hydrolysate of whey } \\
15-20 \% \text { free aminoacids } \\
75-80 \% \text { short chain peptides } \\
\text { Mean chain length } 4 \cdot 5\end{array}$ \\
\hline \multicolumn{3}{|r|}{ 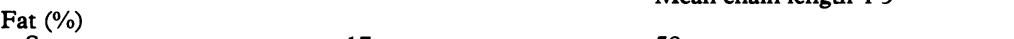 } \\
\hline Saturates & 17 & 58 \\
\hline Monounsaturates & 56 & 11 \\
\hline Polyunsaturates & 26 & 31 \\
\hline Carbohydrate & Maltodextrin & Maltodextrin \\
\hline Emulsifier & $\begin{array}{l}\text { Lecithin (E322) and } \\
\text { Polysorbate (E433) }\end{array}$ & $\begin{array}{l}\text { Mono and diacetyltartric acid } \\
\text { esters of mono and diglycerides } \\
\text { of fatty acids (E472(e)) }\end{array}$ \\
\hline
\end{tabular}

equally effective in clinical use and in reducing intestinal inflammation. Patients with active Crohn's disease, ill enough to otherwise require corticosteroids, and with objective evidence of active inflammation were randomised to treatment with either amino acid or oligopeptide based diet. The two feeds were given in isocaloric quantities and were similar in composition, except that one contained oligopeptides from protein digestion and the other was a chemically defined amino acid based elemental diet. Assessment of response was made by leucocyte scintigraphy in addition to the Crohn's disease activity index $(\mathrm{CDAI})^{20}$ and laboratory measures of disease activity.

\section{Patients and methods}

Patients with Crohn's disease were considered for the trial if they satisfied all three of the following points: they had a least one symptom of active Crohn's disease, for example, diarrhoea, abdominal pain, anorexia, and weight loss; they had a $\mathrm{CDAI}^{20}$ greater than 150 , and they also had at least one abnormal laboratory measurement indicative of active disease. The laboratory measurements considered were haemoglobin concentration, male $<12.5 \mathrm{~g} / \mathrm{dl}$, female $<11.5 \mathrm{~g} / \mathrm{dl}$, platelet count $>400 \times 10^{9} / 1$, erythrocyte sedimentation rate (ESR) $>20$ $\mathrm{mm}$ in the first hour, serum albumin $<35 \mathrm{~g} / \mathrm{l}$,

TABLE II Clinical data of patients in both treatment groups before the beginning of the study

\begin{tabular}{lcc}
\hline & E028 & Pepti-2000 LF Liquid \\
\hline Patients ( $\mathrm{n}$ ) & 22 & 22 \\
Sex M/F & $11 / 11$ & $5 / 17$ \\
Disease location & 7 & 9 \\
$\quad$ Small bowel & 11 & 10 \\
Both small and large bowel & 4 & 3 \\
$\quad$ Large bowel only & $8 \cdot 6$ & $8 \cdot 7$ \\
Years since onset of symptoms (mean) & $0 \cdot 1-30$ & $0 \cdot 3-42$ \\
$\quad$ Range & 6 & 7 \\
Steroid dependent & 7 & 6 \\
Previous surgery & 2 & 0 \\
$\quad$ Right hemicolectomy & 1 & 1 \\
$\quad$ Small bowel resection & 85 & 88 \\
Abdominal mass & $285(164-504)$ & $308(157-450)$ \\
Body weight (\% of ideal body weight) & &
\end{tabular}

$C$ reactive protein $(\mathrm{CRP})>4 \mathrm{mg} / \mathrm{l}$, and $\alpha-1$ acid glycoprotein (AAGP) $>1 \cdot 2 \mathrm{~g} / \mathrm{l}$.

Patients who fulfilled the entry criteria were offered a choice of entry into the trial or treatment with corticosteroids. Forty four patients agreed to participate in the study. Of these 19 were anaemic, 29 had raised platelet counts, 18 had raised ESR, 14 had low albumin, 23 had raised AAGP, and 25 raised CRP. Thirteen patients were receiving longterm prednisolone treatment with a mean daily dose of $14 \mathrm{mg}$ (range 5-40 mg). The duration of previous corticosteroid treatment ranged from two months to 10 years (median 18 months). In all 13 patients previous attempts to withdraw corticosteroids had failed.

Figure 1 shows the study design. Patients were assessed at entry, at day 10 , and weekly thereafter. Clinical disease activity was quantified by the CDAI and laboratory measures of activity (haemoglobin, platelet count, ESR, AAGP, and CRP). Total body weight, percentage of ideal body weight, and serum albumin concentration were used to assess the nutritional state. Thirty five patients were also assessed by technetium isotope hexamethylpropylene-amine-oxime ( $\left.{ }^{99 \mathrm{~m}} \mathrm{Tc}-\mathrm{HMPAO}\right)$ labelled leucocyte scanning. The scintigraphic images of abnormal bowel uptake were quantified by computer aided image analysis with background subtraction, ${ }^{21}$ to produce a scan score reflecting the severity and extent of bowel inflammation. The pretreatment scan scores ranged from $6 \cdot 7$ to 380 (mean=97). A value of 20 has previously been defined as being the upper limit consistent with inactive disease. ${ }^{22}$ The one patient with a scan score below 20 (6.7) had extensive active colonic disease shown at colonoscopy immediately before entry into the trial. A repeat ${ }^{99 \mathrm{~m} T \mathrm{~T}-\mathrm{HMPAO}}$ scan was performed in 21 patients at the end of diet treatment to measure the change in gut inflammation in response to treatment.

After initial assessment the patients were randomised to one of the two treatment groups; 22 patients were treated with amino acid based 'Elemental 028' (E028, Scientific Hospital Supplies, Liverpool, UK) and 22 patients received the oligopeptide based diet 'Pepti-2000 LF liquid' (Cow and Gate, Trowbridge, Wiltshire, UK). Table I compares the nutritional composition of the two diets. Neither diet contained carrageenan, an emulsifying agent that can cause bowel inflammation in animals, and which it has been suggested may have similar effects in humans. ${ }^{13}$ Randomisation was stratified for site of disease between the three categories, small bowel, colonic, and both small and large bowel.

Both diets were given through a fine bore nasogastric tube ('Silk' tube, Corpak Inc, via E Merck Pharmaceuticals, Alton, Hampshire, UK). Each patient received an average of 2250 kcal daily. During the treatment only tap or bottled water was permitted orally. The E028 diet was reconstituted freshly by the patient as required using boiled tap water. All previous treatment including corticosteroids was gradually withdrawn during the first 12 days. 
TABLE III Laboratory data of patients in both treatment groups at the beginning of the study. (Mean (SEM))

\begin{tabular}{lll}
\hline Normal & $\begin{array}{l}\text { E028 } \\
(n=22)\end{array}$ & $\begin{array}{l}\text { Pepti-2000 LF } \\
\text { Liquid }(n=22)\end{array}$ \\
\hline Haemoglobin & & \\
Male $>12 \cdot 5 \mathrm{~g} / \mathrm{dl}$ & & \\
Female $>11.5 \mathrm{~g} / \mathrm{dl}$ & $11.9(0 \cdot 3)$ & $11 \cdot 6(0 \cdot 4)$ \\
ESR $<20 \mathrm{~mm} / \mathrm{h}$ & $22(3)$ & $22(3)$ \\
Platelets $<400 \times 10^{9} / 1$ & $439(26)$ & $487(32)$ \\
CRP $<4 \mathrm{mg} / 1$ & $35(10)$ & $29(11)$ \\
AAGP $<1 \cdot 2 \mathrm{~g} / 1$ & $1 \cdot 44(0 \cdot 1)$ & $1 \cdot 56(0 \cdot 2)$ \\
Albumin $>35 \mathrm{~g} / 1$ & $37(1 \cdot 1)$ & $36(1 \cdot 2)$ \\
99m Tc HMPAO scan score & $96(16)$ & $98(24)$ \\
(>20=active disease) & & \\
\hline
\end{tabular}

Treatment was started in hospital but patients were permitted home once they had stabilised while taking the enteral feed, usually within five days of starting.

Clinical remission was defined as a combination of a reduction in CDAI of 100 points or $40 \%$ of the initial value, control of symptoms, and withdrawal of all treatment including corticosteroids. The CDAI criteria for remission was the same as that used in a recent large European trial of dietary treatment. ${ }^{19}$

Analysis of the results was performed on an intention to treat basis using Fisher's exact test. The effect of treatment on laboratory and clinical indices was assessed by the paired Student $t$ test. The study size was chosen to differentiate between response rates of $75 \%$ and $40 \%$ at $95 \%$ confidence limits.

This study was approved by the ethical committee for the former United Sheffield hospitals. Patients gave informed consent before entry. The patients were entered between August 1989 and January 1993.

\section{Results}

Table II compares the treatment groups at the beginning of treatment. They were well matched for previous surgery, time since initial onset of symptoms, corticosteroid dependence, extent of malnutrition, and clinical disease activity. Laboratory indices of activity and ${ }^{99 m}$ Tc-HMPAO scan scores were also similar (Table III).

Table IV shows the overall outcome at the end of 28 days of treatment. Six patients withdrew from the study within the first week because they found nasogastric feeding more inconvenient than anticipated. Sixteen patients achieved clinical remission defined by control of symptoms, withdrawal of all treatment, and a reduction in CDAI of 100 points or $40 \%$ from the initial value. Twenty two patients failed to achieve this definition of remission. Of these, 12 patients were withdrawn before 28 days because of failure to show satisfactory

TABLE IV Outcome

\begin{tabular}{lcc}
\hline & E028 & $\begin{array}{c}\text { Pepti-2000 } \\
\text { LF Liquid }\end{array}$ \\
\hline Randomised & 22 & 22 \\
Intolerant of nasogastric feeding & 3 & 3 \\
Failure to achieve remission & 11 & 11 \\
Clinical remission & 8 & 8 \\
$\quad$ (defined as CDAI reduction of & & \\
\hline 100 points or 40\%) & & \\
\hline
\end{tabular}

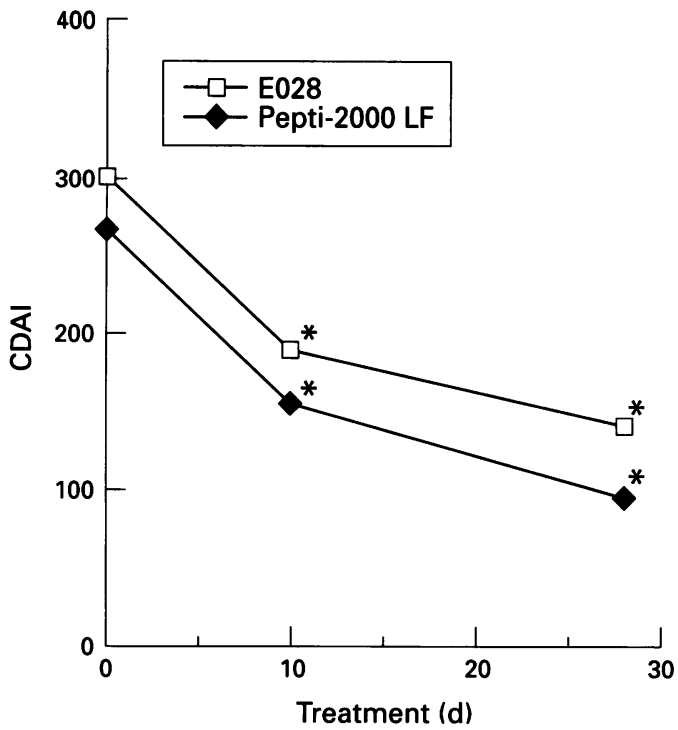

Figure 2: Mean changes in $C D A I$ during treatment in patients responding to diet. * Significantly different from initial value, $p<0.02$.

progress, while 10 improved clinically and completed the 28 days of treatment but did not fulfil the strict definition of remission.

The two diets, E028 and Pepti-2000 LF Liquid had identical rates of remission, failure, early withdrawal, and intolerance of nasogastric feeding. With each diet there were some patients in whom the response was very spectacular, with falls of more than $80 \%$ of the initial CDAI value being recorded. Among all the responding patients the rate of improvement was greatest during the initial 10 days of treatment with a slower but sustained improvement in the final 18 days (Fig 2).

In addition to the clinical improvement there was a reduction in CRP in patients achieving clinical remission $(p=0 \cdot 05)$. In those who started the study with a low serum albumin there was a rise. The other laboratory markers of disease activity (haemoglobin, ESR, platelets, AAGP) and nutritional state (body weight, $\%$ ideal body weight) were unchanged by treatment (Table V).

In patients who showed the most spectacular clinical response there was an obvious reduction in inflammatory activity on leucocyte scanning. Figure 3 shows examples of three pairs of scans. Figure 4 plots the results of all the pairs of scans.

The results were analysed to see which particular features of disease were predictive of remission and whether any features precluded a successful response to diet treatment. Some patients of each sex responded rapidly, but in patients intolerant of nasogastric feeding there was a high proportion of men. Analysis by disease location showed that remission was achieved in eight of 16 patients with only small bowel disease, six of 21 with disease at both sites, and two of seven with only colonic disease. Patients with more severe disease, assessed by either CDAI $>300$ or by a scan score greater than 100 , did not show a different rate of response to those with less severe disease. Those with a duration of symptoms of more than five years had a lower remission rate $(27 \%)$ compared with those with a shorter 
TABLE $\mathrm{V}$ Laboratory findings at entry and at four weeks in patients responding to diet. (Mean (SEM))

\begin{tabular}{lcccc}
\hline & \multicolumn{2}{l}{ O028 $(n=8)$} & \multicolumn{2}{c}{ Pepti-2000 LF $(n=8)$} \\
\cline { 2 - 5 } & Day 0 & Day 28 & Day 0 & Day 28 \\
\hline Haemoglobin $(\mathrm{g} / \mathrm{dl})$ & $12 \cdot 5(0 \cdot 5)$ & $12 \cdot 3(0 \cdot 5)$ & $11 \cdot 1(0 \cdot 6)$ & $11 \cdot 6(0 \cdot 6)$ \\
ESR $(\mathrm{mm} / \mathrm{h})$ & $17(4)$ & $18(5)$ & $24(7)$ & $17(3)$ \\
Platelets $\left(\times 10^{9} / \mathrm{l}\right)$ & $389(38)$ & $403(49)$ & $510(57)$ & $378(41)$ \\
CRP $(\mathrm{mg} /)$ & $11(6)$ & $6(4)^{\star}$ & $48(23)$ & $0^{\star}$ \\
AAGP $(\mathrm{g} / \mathrm{l})$ & $1 \cdot 2(0 \cdot 1)$ & $1 \cdot 1(0 \cdot 2)$ & $1 \cdot 6(0 \cdot 4)$ & $0 \cdot 9(0 \cdot 1)$ \\
Albumin $(\mathrm{g} / \mathrm{l})$ & $39(1 \cdot 5)$ & $39(1 \cdot 9)$ & $37(2 \cdot 2)$ & $40(1 \cdot 4)$ \\
$\%$ ideal body weight & $83(5)$ & $83(5)$ & $92(4)$ & $95(4)$ \\
\hline
\end{tabular}

*In combined group of all responders, CRP day $0 v$ CRP day 28, $\mathrm{p}=0 \cdot 05$. No other change reaches statistical significance ( $t$ tests).

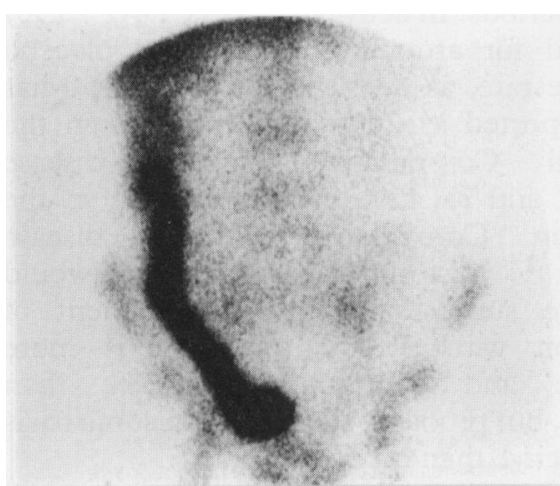

Before treatment

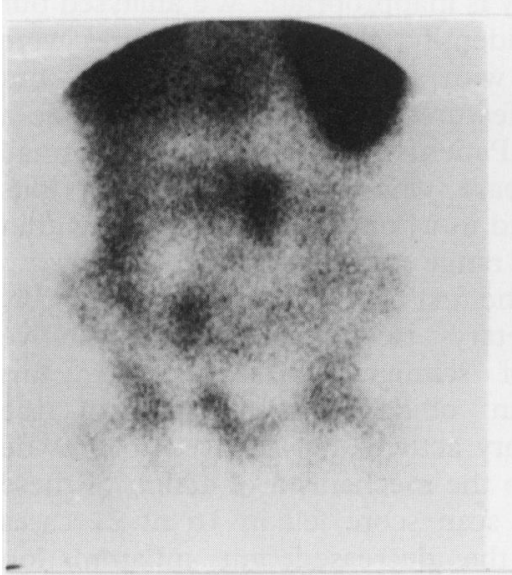

Before treatment

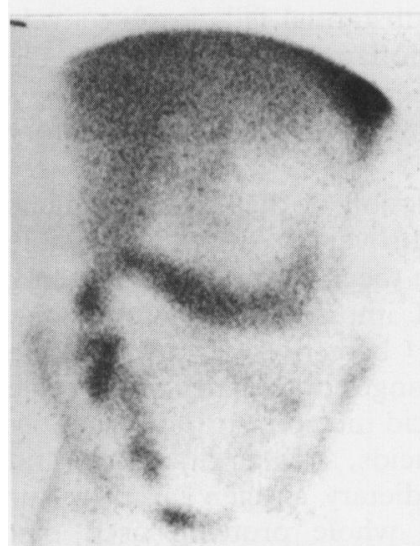

Before treatment

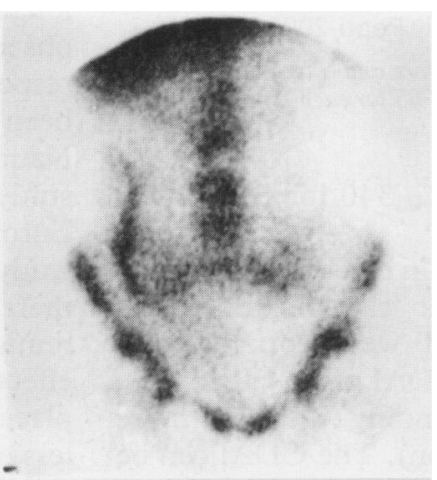

After treatment

\section{After treatment}

Figure 3: Examples of ${ }^{99 \mathrm{~m}}$ Tc-HMPAO scans before and after diet treatment showing reduction in active inflammation. history (50\%). Previous dependence on corticosteroids did not preclude successful response (three of 13 corticosteroid dependent $v 13$ of 31 not receiving corticosteroids, reached remission). Patients who had had previous bowel surgery entailing a resection had slightly lower success rates. A low pretreatment serum albumin (below $35 \mathrm{~g} / \mathrm{l}$ ) was also associated with a lower response rate: $29 \% v$ $41 \%$. The study size was, however, too small for these subgroup analyses to reach statistical significance.

Four patients who had improved while receiving diet treatment but had not achieved remission required no immediate treatment after completion of the study. Fifteen of the remaining 18 patients, who had failed to achieve remission, were subsequently treated with corticosteroids. One patient opted to try E028, having improved only slightly during the initial 10 days of treatment with Pepti-2000 LF Liquid. She continued to improve and reached remission but is counted as a treatment failure in the above analysis. Four patients had surgery after failing to respond to the diet treatment. Of these one operation was for a perianal abscess, one for obstructive symptoms, and the other two for persistently active inflammatory disease, which had also failed to respond to corticosteroid treatment.

\section{Discussion}

This randomised controlled study has confirmed that both a peptide based enteral feed and an amino acid based elemental diet can induce remission in active Crohn's disease. They can be used as the sole treatment, and can be effective regardless of the site or duration of the disease. Some patients who have previously been corticosteroid dependent may also respond to treatment by enteral feeding, permitting withdrawal of oral corticosteroids as reported previously. ${ }^{10}$

The amino acid and peptide based diets each achieved the same rate of remission. Some patients in each group had a dramatic response with rapid resolution of symptoms. This rapid response is in keeping with previous reports ${ }^{1423}$ and has also been seen in clinical trials in which amino acid based diets have been compared with corticosteroids. ${ }^{16-18}$ The two diets used in our study had similar carbohydrate and fat proportions (Table I), and differed only in their amino acid presentation. E028 being chemically defined contains single amino acids, while Pepti-2000 LF Liquid is derived from hydrolysed whey protein with mean chain length 4.5 amino acids. Because the minimum peptide chain length for antigen presentation is eight amino acids, both diets can be considered to be free of food antigens. From the practical point of view the finding that an oligopeptide based diet seems to be as effective as an amino acid based formula is important, as protein hydrolysates are generally more palatable and can be prepared more cheaply than amino acid based chemically defined diets. At 1992 list prices 28 days of treatment with these diets 


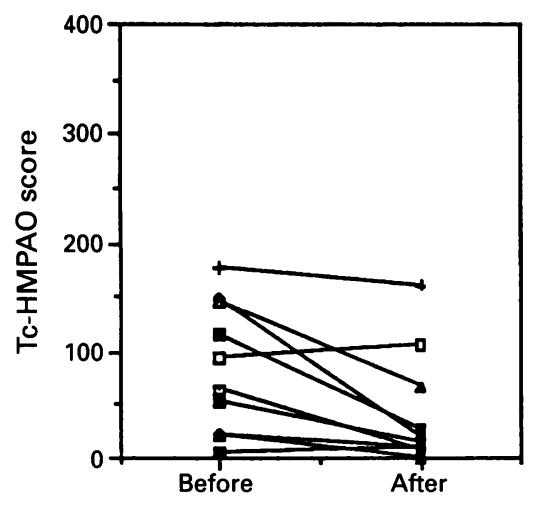

E028

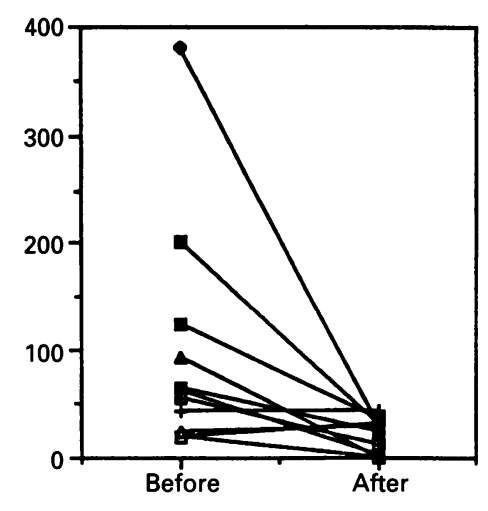

Pepti-2000 LF

Figure 4: ${ }^{99 \mathrm{~m}}$ Tc-HMPAO scan scores of individual patients before and after diet treatment: E028 v Pepti-2000 LF Liquid. Student's t test $p<0.05$ for each group.

cost $£ 606$ for E028 and $£ 340$ for Pepti-2000 LF Liquid.

The patients included in this study represent a group of patients who can be difficult to treat. Nearly one third were corticosteroid dependent, half had a CDAI greater than 300, and most had longstanding disease (more than five years of duration). The CDAI can be raised by non-inflammatory complications of Crohn's disease, such as malnutrition, bowel strictures or depression. ${ }^{24} \mathrm{We}$, therefore, deliberately identified only those patients in whom the inflammatory disease process was active both clinically and on objective laboratory measures of activity. This has permitted us to compare in a controlled trial the ability of these diets to specifically reduce active inflammation.

The trial design included administration of the enteral feed by nasogastric tube in all patients. Both of the diets are moderately unpalatable and although some centres prefer to give them as sip feeds this has an unacceptable intolerance rate of 20 of 51 patients in a recent study. ${ }^{25}$ Administration by this route also permitted us to be sure that the feed supplied was actually given. In some studies weight loss during treatment must cast doubt on whether this was actually achieved. ${ }^{26}$

Published works contain reports of diet treatment in retrospective series, ${ }^{27} 28$ nonrandomised trials, ${ }^{29}$ and prospective randomised trials. ${ }^{711-14}$ 16-19 26 The theoretical ideal of a double blind controlled trial has been performed to compare elemental and polymeric diets but only seven patients were entered into each limb. ${ }^{14}$ The retrospective series have reported very high response rates, such as 96 of 113 patients, ${ }^{28}$ and have shown the need for prospective trials. A formal metaanalysis of the published trials is impossible because the trials differ in patient selection criteria, clinical indices used to follow response, definitions of remission, choice of diets, methods of administration, durations of treatment, and protocols for starting, continuing or withdrawing additional drug treatment. Also some studies cannot be directly compared as they have reported the results in terms of the overall response of the whole group rather than the number of subjects responding. ${ }^{7}$ 16-18 Our remission rate is lower than some of the

previous trials, possibly because of the stricter definition of remission and the deliberate choice of patients with active inflammation. All the randomised studies that have reported results as response rates and have used oligopeptide or amino acid based diets, or both, now include 179 patients of which $100(56 \%)$ reached 'remission', 11-14 1926 although the definition of remission varies between studies.

There have been no placebo controlled trials of diet treatment in active Crohn's disease. The placebo findings in published reports are of remissions usually achieved after much longer periods. In active disease (CDAI >150) observed for around 100 days the placebo response rate, as defined by CDAI $<150$ has been reported as $26 \%$ in 77 patients in the National Co-operative Crohn's disease study, ${ }^{30}$ and as $42 \%$ in 110 patients in the European Co-operative Crohn's disease study. ${ }^{31} 32$ Historical comparisons would therefore suggest that the achievement of remission with dietary treatment is more effective and substantially quicker than placebo, but probably slower and in some trials less effective than corticosteroids.

All the studies agree that some patients will respond to diet treatment, and that it therefore has a useful role as an alternative where corticosteroids are undesirable, or have failed and surgery is inappropriate. We analysed our results to identify whether any features were associated with a higher remission rate, but found no features that seemed to preclude a response. Patients with recent onset small bowel disease who had not had previous surgery, and in whom the albumin was within the normal range seem to do best.

This is the first clinical trial to prospectively assess dietary treatment by quantitative analysis of scintigraphic images. By this method an objective assessment of the inflammatory activity can be used to provide insight into the mechanism of action of these diets. The scan score fell in 16 of 21 cases reflecting the decreased gut inflammation after treatment. The scan scores did not all fall to within the inactive range, which is consistent with the persistence of histological activity long after a clinical response. The failure to achieve clinical remission in some patients despite substantial falls in objectively measured bowel inflammation highlights the discordance between subjective clinical indices and objective measures of inflammatory activity. ${ }^{24}$

The mode of action of these diets remains a point of controversy. Several possible mechanisms have been suggested including purely nutritional improvement, bowel rest, changes to the bacterial flora, immune modulation by changes in the fatty acid profile (by arachidonic acid metabolism), direct effect of certain amino acids, such as glutamine, and reduction in the dietary antigen load. In our previous study a whole protein based diet seemed less effective than an amino acid based diet, ${ }^{11}$ lending some support to the antigen load theory, although subsequently other studies, in some of which malnutrition was 
more prominent in the patients before treatment, have found protein containing diets to be effective. ${ }^{12-1433}$ Even in formula diets containing intact protein, the dietary antigen load is considerably changed, as the protein is usually derived from a single source, usually milk. It may be that further animal models of Crohn's disease will be required before these different theories can be fully tested. ${ }^{34}$ In this study we have evidence that the oligopeptide and amino acid based diets are exerting a specific anti-inflammatory effect by the reduction in leucocyte migration seen and quantified in the scintigraphic images. Further evidence comes from the reports of decreased protein loss and improvements in abnormal intestinal permeability with diet treatment. ${ }^{3-5}$ The concept that luminal contents can in some way modulate activity of inflammation in Crohn's disease is also supported by the finding that diversion of the faecal stream after resective surgery prevents anastomotic recurrence. ${ }^{35} \mathrm{It}$ may therefore be that formula diets reduce or remove some factors responsible for perpetuation of inflammation. Even in cases of small bowel disease the crucial site may be the colonic mucosa, ${ }^{36}$ although changes in bacterial flora in the colon have been sought and are not seen with elemental diet treatment. ${ }^{37}$ Immunological analysis of the effects of diet treatment have shown a decrease in HLA-DR antigen expression in the colon and a reduction in gut lavage fluid concentrations of soluble interleukin 2 receptor, ${ }^{38} 39$ but details of the actual therapeutic mechanism remain unclear.

In conclusion, elemental diet is not a panacea in active Crohn's disease. There are patients who respond rapidly and go into complete remission, but there are also patients who derive little or no benefit from it. In those patients who respond there is often an almost total abolition of gut inflammation as shown by scintigraphy in this study. This is further evidence that the effect is more than merely nutritional improvement. We have found an oligopeptide and an amino acid based diet to be equally effective at inducing remission in active Crohn's disease. In some patients either of these types of diet can provide a useful alternative to corticosteroid treatment or surgery.

We thank the nursing staff in ward J1 at the Royal Hallamshire Hospital, the dietetics department, particularly Susan Jones, and the medical physics department for their help with this study; and our patients for their cooperation.

The research was supported by a grant from Cow and Gate (Nutricia). We are also grateful to Scientific Hospital Supplies for supplying E028 at reduced cost.

Some of the results of this study have been published in abstract form: Gut 1992; 33 (suppl 2): S3.

1 Culpepper-Morgan JA, Floch MH. Bowel rest or bowel starvation: defining the role of nutritional support in the treatment of inflammatory bowel disease. $A m, \mathcal{J}$ Gastroenterol 1991; 86: 269-71.

$2 \mathrm{Klein} \mathrm{S}$. Elemental versus polymeric feeding in patients with Crohn's disease - is there really a winner? Gastroenterology 1990; 99: 893-4.

3 Logan RFA, Gillon J, Ferrington C, Ferguson A. Reduction of gastrointestinal protein loss by elemental diet in Crohn's disease of the small bowel. Gut 1981; 22: 383-7.

4 Sanderson IR, Boulton P, Menzies I, Walker-Smith JA Improvement of abnormal lactulose/rhamnose permeability in active Crohn's disease of the small bowel by an elemental diet. Gut 1987; 28: 1073-6.

5 Teahon K, Smethurst P, Pearson M, Levi AJ, Bjarnason I. The effect of elemental diet on permeability and inflam - mation in Crohn's disease. Gastroenterology 1991; 101: 84-9.

6 Morin CL, Roulet M, Roy CC, Weber A, Lapointe N. Continuous elemental enteral alimentation in the treatment of children and adolescents with Crohn's disease. mPEN 1982; 6: 194-9.

7 Sanderson IR, Udeen S, Davies PSW, Savage MO, WalkerSmith JA. Remission induced by an elemental diet in small bowel Crohn's disease. Arch Dis Child 1987; 61 123-7.

8 Belli DC, Seidman E, Bouthillier L, Weber AM, Roy CC Pletincx $M$, et al. Chronic intermittant elemental die improves growth failure in children with Crohn's disease. Gastroenterology 1988; 94: 603-10.

9 Giaffer MH, Cann P, Holdsworth CD. Long-term effects of elemental and exclusion diets for Crohn's disease. Aliment Pharmacol Ther 1991; 5: 115-25.

10 O'Brien CJ, Giaffer MH, Cann P, Holdsworth CD. Elemental diet in steroid-dependent and steroid-refractory Crohn's disease. Am $f$ Gastroenterol 1991; 86: 1614-8.

11 Giaffer MH, North G, Holdsworth CD. Controlled trial of polymeric versus elemental diet in treatment of active Crohn's disease. Lancet 1990; 335: 816-9.

12 Rigaud D, Cosnes J, Le Quintrec Y, Rene E, Gendre JP, Mignon $M$. Controlled trial comparing two types of enteral nutrition in treatment of active Crohn's disease: elemental $v$ polymeric diet. Gut 1991; 32: 1492-7.

13 Raouf AH, Hildrey V, Daniel J, Walker RJ, Krasner N, Elias E, et al. Enteral feeding as sole treatment for Crohn's disease: controlled trial of whole protein $v$ amino acid based feed and a case study of dietary challenge. Gut 1991; 32: 702-7.

14 Park RHR, Galloway A, Danesh BJZ, Russell RI. Doubleblind controlled trial of elemental and polymeric diets as primary therapy in active Crohn's disease. Eur primary therapy in active Crohn'

15 Payne-James J, Silk DBA. Use of elemental diets in the treatment of Crohn's disease by gastroenterologists [letter]. Gut 1990; 31: 1424.

16 O'Morain C, Segal AW, Levi AJ. Elemental diet as primary reatment of acute Crohn's disease: a controlled trial. $B M F$ 1984; 288: 1859-62.

17 Hunt JB, Payne-James JJ, Palmer KR, Kumar PK, Clark ML, Farthing MJG, et al. A randomised controlled trial of elemental diet and prednisolone as primary therapy in acute exacerbations of Crohn's disease. Gastroenterology 1989; 96: A226.

18 Saverymuttu S, Hodgson HJF, Chadwick VS. Controlled trial comparing prednisolone with an elemental diet plus on-absorbable antibiotics in active Crohn's disease Gut 1985; 26: 994-8.

19 Lochs H, Steinhardt HJ, Klaus-Wentz B, Zeitz M Vogelsang $\mathrm{H}$, Sommer $\mathrm{H}$, et al. Comparison of entera nutrition and drug treatment in active Crohn's disease. Results of European Co-operative Crohn's disease study IV. Gastroenterology 1991; 101: 881-8.

20 Best WR, Becktel JM, Singleton JW, Kern F. Development of a Crohn's disease activity index. National Co-operative Crohn's disease study. Gastroenterology 1976; 70: 439-44.

21 Tindale WB, Barber DC, Giaffer MH, Senior S, Holdsworth CD. 99m Tc HMPAO-labelled leucocyte imaging in Crohn's disease: a subtraction technique for the quantification of disease activity. Clin Phys Physiol Meas 1992; 13: 37-50.

22 Giaffer MH, Tindale WB, Senior S, Barber DC, Holdsworth CD. Quantification of disease activity in Crohn's disease by computer analysis of Tc- $99 \mathrm{~m}$ hexamethyl propylene amine oxime (HMPAO) labelled leucocyte images. Gut 1993; 34: 68-74

23 O'Morain C, Segal AM, Levi AJ, Valman HB. Elementa diet in acute Crohn's disease. Arch Dis Child 1983; 53: $44-7$.

24 Hodgson HJF, Mazlam MZ. Review article: assessment of drug therapy in inflammatory bowel disease. Aliment Pharmacol Therap 1991; 5: 555-84.

25 Malchow H, Steinhardt HJ, Lorenz-Meyer H, Strohm WD, Rasmussen S, Sommer H, et al. Feasibility and effectiveness of a defined-formula diet regimen in treating active Crohn's disease. European Co-operative Crohn's disease Crohn's disease. European Co-operative Crohn's
study III. Scand f Gastroenterol 1990; 25: 235-44.

26 Middleton SJ, Riordan AM, Hunter JO. Peptide based diet: an alternative to elemental diet in the treatment of acute Crohn's disease. Gut 1991; 32: A578.

27 O'Morain C, Segal AW, Levi AJ. Elemental diets in treatment of acute Crohn's disease. BMF 1980; 281: 1173-5.

28 Teahon K, Bjarnason I, Pearson M, Levi AJ. Ten years experience with an elemental diet in the management of Crohn's disease. Gut 1990; 31: 1133-7.

29 Okada M, Yao T, Yamamoto T, Takenaka K, Imamura K, Maeda $\mathrm{K}$, et al. Controlled trial comparing an elemental diet with prednisolone in the treatment of active Crohn's diet with prednisolone in the treatment of active
disease. Hepatogastroenterology 1990; 37: 72-80.

30 Summers RW, Switz DM, Sessions JT, Becktel JM, Best WR, Kern F, et al. National Co-operative Crohn's disease study: results of drug treatment. Gastroenterology 1979; 77: 847-69.

31 Melchow H, Ewe K, Brandes JW, Goebell H, Ehms H, Sommer $\mathrm{H}$, et al. European Co-operative Crohn's disease Sommer H, et al. European Co-operative Crohn's disease
study (ECCDS): results of drug treatment. study (ECCDS): results of

32 Meyers S, Janowitz HD. 'Natural history' of Crohn's disease. An analytical review of the placebo lesson. Gastroenterology 1984; 87: 1189-92.

33 González-Hiux F, de León R, Fernández-Bañares $F$, 
Esteve M, Cabré E, Acero D, et al. Polymeric enteral diets as primary treatment of active Crohn's disease: a prospective steroid controlled trial. Gut 1993; 34: a prosp

34 Stoker TW, Casanova JE, Sanderson IR, Schiffrin EJ, Israel EJ, Carter EA. Diet and disease response in an animal model for inflammatory bowel disease. Gastroenterology 1993; 104: A1063.

35 Rutgeerts P, Goboes K, Peeters M, Hiele M, Penninckx F, Aerts $R$, et al. Effect of faecal stream diversion on recurrence of Crohn's disease in the neoterminal ileum. Lancet 1991; 338: 771-4.

36 Olaison G, Smedh K, Sjodahl R. Recurrence of Crohn's disease in the neo-terminal ileum and colonic factors [letter]. Lancet 1991; 338: 1401.

37 Giaffer MH, Holdsworth CD, Duerden BI. Effect of elemental diet on the faecal flora in patients with Crohn's disease. Microbial Ecology in Health and Disease 1991; 4: disease.

38 Chiba M, lizuka M, Horie Y, Igarashi K, Masamune O. HLA-DR antigen expression in macroscopically uninvolved areas of intestinal epithelia in Crohn's disease. Gastroenterol fpn 1989; 24: 365-72.

39 Mwantembe O, Ferguson A. Immunological effects of elemental diet in inflammatory bowel disease - a prospective study. Gut 1991; 32: A1228. 